\title{
Association of soybean-based food with the prevalence of anaemia among reproductive-aged men and women in rural Central Java, Indonesia
}

\author{
Callum Lowe ${ }^{1, *}$, Haribondhu Sarma ${ }^{1}$ (1), Matthew Kelly ${ }^{1}$, Johanna Kurscheid ${ }^{1,2}$, \\ Budi Laksono $^{3}$, Salvador Amaral ${ }^{1}$, Donald Stewart ${ }^{1,4}$ and Darren Gray ${ }^{1}$ \\ ${ }^{1}$ Australian National University, Acton 2601, Australia: ${ }^{2}$ Swiss Tropical and Public Health Institute, Basel 4051, \\ Switzerland: ${ }^{3}$ Universitas Diponegoro, Semarang 50275, Indonesia: ${ }^{4}$ Griffith University, South Brisbane, QLD, \\ Australia
}

Submitted 6 October 2021: Final revision received 8 December 2021: Accepted 21 December 2021: First published online 27 December 2021

\begin{abstract}
Objective: To assess the association between soybean consumption and anaemic status in Central Java, Indonesia.

Design: As part of an overarching sanitation improvement intervention in Central Java, Indonesia, we conducted a cross-sectional study in four rural villages. The study consisted of a 24-h food recall, anthropometric measurements, blood $\mathrm{Hb}$ measurement and stool sampling to test for soil-transmitted helminth (STH) infection status. A binary logistic regression model was fitted to test the association between soybean consumption and anaemic status after adjusting for socio-demographic factors, STH infection, dietary diversity and anthropometric status.

Setting: This study took place in four rural villages of Wonosobo regency, Central Java, Indonesia.

Participants: Participants were rural villagers aged between 15 and 49 years.

Results: A total sample size of 763 was attained, of which 231 were anaemic. The prevalence of anaemia was $30.2 \%$ among men and women of reproductive age, and highest among young males. Consumption of soybean was high (79.8\%). After adjusting for covariates, the protective association between soybean consumption and anaemia was statistically significant (AOR $=0.53,95 \% \mathrm{CI}=0.30,0.95$, $P<0.05)$. There was a positive association with anaemia among underweight $(\mathrm{AOR}=2.75,95 \% \mathrm{CI}=1.13,6.69, P<0.05)$ and those with high diet diversity $(\mathrm{AOR}=1.40,95 \% \mathrm{CI}=1.00,1.97, P<0.05)$.

Conclusions: Our results were consistent with studies from other countries finding a protective association between soybean consumption and anaemia. This association appeared stronger for tofu than for tempeh. The prevalence of anaemia in rural Central Java is relatively consistent with nation-wide statistics indicating that interventions targeting anaemia are still largely required.
\end{abstract}

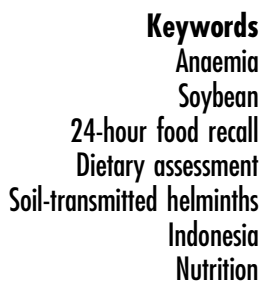

Anaemia is a condition where $\mathrm{Hb}$ concentrations are below the normal level to meet a person's physiological needs, and affects one-third of the world's population ${ }^{(1)}$. Anaemia can cause compromised immune system function, weakness and cognitive dysfunction ${ }^{(2)}$. Whilst the causes are multi-factorial, there is increasing awareness of the contribution of helminthiases ${ }^{(3)}$. Fe-deficiency anaemia (IDA) caused by nutritional Fe deficiency is the most common cause of anaemia ${ }^{(2)}$ and a national problem in Indonesia $^{(4)}$. Over the last decade, the

prevalence of anaemia in Indonesia has steadily increased $^{(5)}$ following a downward trend observed between 1997 and $2008^{(6)}$. Limited literature exists on the causes of this increase, although it is possible that the rising rates of overweight/obesity are responsible as these conditions are also associated with anaemia ${ }^{(7)}$. In 2018, the prevalence of anaemia among pregnant women nationwide was estimated at $48.9 \%{ }^{(6,8)}$. No population-wide estimate of anaemia prevalence across all demographics in Indonesia has been reported in over 
a decade, but more recent studies still report high prevalence, with one 2016 study finding $40.7 \%$ of pregnant Indonesian women in North Sumatra anaemic ${ }^{(9)}$.

Pregnant women represent one of the most at-risk groups for anaemia because of the increased requirements of Fe during pregnancy ${ }^{(10)}$. One of the major interventions that is part of national policy in Indonesia towards IDA is Fe supplementation for pregnant women and wheat flour fortification with $\mathrm{Fe}^{(11)}$. The effectiveness of Fe supplementation however has been compromised. Two major obstacles have been faced - not meeting supplementation frequency and amount requirements among young women ${ }^{(12)}$ and discontinuation of supplement use among Indonesian women during pregnancy ${ }^{(11,13)}$. Among adolescent girls, anaemia is of greater risk due to the onset of menstruation and increase in muscle mass and blood volume ${ }^{(14-16)}$. This is of great concern in Indonesia whereby misinformation surrounding the risks and prevention of anaemia has been reported by adolescent girls and their parents ${ }^{(17)}$. Often forgotten however is the danger of anaemia among men, where similar symptoms that appear in women such as lethargy and fatigue are common, but are also thought to contribute to decreased economic productivity ${ }^{(18)}$. Fe supplementation in Indonesia is only recommended for pregnant women, and so other demographics such as men are not subject to these direct interventions.

Factors associated with anaemia commonly observed include low socio-economic status ${ }^{(19)}$, low education ${ }^{(19-22)}$, discontinued use of Fe supplements ${ }^{(21,22)}$, low dietary diversity ${ }^{(20,23)}$ and helminth infections ${ }^{(24)}$. Hookworm infection contributes to anaemia as it feeds off its host's blood causing blood loss ${ }^{(25)}$. In Indonesia, the association between hookworm infection and anaemia has been observed $(\mathrm{OR}=2 \cdot 6$, $95 \% \mathrm{CI}=1.2,5 \cdot 8, P<0.05)^{(24)}$. Low dietary diversity can mean low consumption of bioavailable Fe as well as deficiency of minerals and vitamins that increase the bioavailability of Fe. This is supported by a study among adolescent girls in West Java, Indonesia, that found lower consumption of meat, chicken and fish as well as lower diet quality was associated with anaemia ${ }^{(26)}$. While animal foods such as those mentioned provide a rich source of bioavailable $\mathrm{Fe}^{(27)}$, meat consumption in Indonesia is the 16th lowest in the world and lower than other south-east Asia countries ${ }^{(28)}$.

Soybean is a high Fe containing legume ${ }^{(29)}$ and is a staple in the Indonesian $\operatorname{diet}^{(30)}$. Due to its elevated Fe content, the association between soybean and soybean-based food consumption with anaemia has been explored in much literature $^{(29,31-34)}$. Pregnant women consuming an optimised diet with fermented soybean and vitamin C-rich fruit (vitamin $\mathrm{C}$ increases absorption of $\mathrm{Fe}^{(29)}$ ) in Indonesia have been demonstrated to experience a smaller decrease in serum $\mathrm{Hb}$ concentration during pregnancy ${ }^{(29)}$. Among Chinese adults, the consumption of tofu, a soybean-based product, is associated with reduced odds of anaemia $(\mathrm{AOR}=0 \cdot 30,95 \% \mathrm{CI}=0 \cdot 20,0 \cdot 47)^{(32)}$. Little research however has been conducted to evaluate this association in
Indonesia, despite wide prevalence of anaemia and soybean consumption. The two major soybean products consumed in Indonesia - tofu and tempeh which make up $70 \%$ of soybean consumption ${ }^{(30)}$ - have not yet been studied together in relation to anaemia, and the existing consumption of them needs to be quantified to assess their potential role as part of an anaemia intervention.

In the Indonesian context where the prevalence of anaemia is rising, other public health interventions need to be introduced alongside Fe supplementation to curb this rise. The identification of simple, culturally acceptable foods may aid existing interventions. Given this situation and the aforementioned gaps in the literature, our study aimed to assess the association between consumption of soybeanbased food, the prevalence of anaemia and interactions with STH infection status among rural villagers in Central Java, Indonesia.

\section{Methods}

\section{Study design and sample}

This nutrition study is part of an overarching sanitation improvement intervention in rural Central Java, Indonesia. A cross-sectional study design was employed where a 24-h food recall was conducted and anthropometric and blood-Hb measurements were taken. Participants in the study were from four rural villages in Central Java, Indonesia. These villages are located on the outskirts of the district town Wonosobo and on the foothills of neighbouring mountains Mt. Bismo and Mt. Sindoro. This overarching study was a community-based cluster-randomised intervention trial where eight villages were selected on the basis of low levels of household latrine ownership, and stratified by topography (four mountain Dusun and four hillside Dusun). The villages were further stratified into control and intervention groups. The four villages selected for this study comprised the control villages for the intervention. Data collection was carried out in NovemberDecember 2018. From each village, 110 households were randomly selected and all members of those households aged 3 years and over were invited to join the study. After the 1-year follow-up of the study, participants in control villages were approached again and invited to take part in the nutrition survey. At baseline, a total of 1876 participants took part in the sanitation improvement intervention. At follow-up, a total of 1521 participants from the four control villages took part in the nutrition survey.

\section{Data collection}

Dietary intake data was collected from a 24-h food recall. For this study, only participants aged between 15 and 49 years old with complete data were used in analysis because of the heightened risk of anaemia among adolescents and women of reproductive age $\mathrm{e}^{(10,14-16)}$. This resulted in a final 
sample size of 763 participants. The 24 -h food recall was a semi-structured questionnaire administered by trained data collectors. Data collectors were local health staff with knowledge of locally relevant food types. Participants were asked to provide a recount of the foods and beverages they consumed in the past $24 \mathrm{~h}$ including the amounts (number of cups, pieces or glasses where relevant), side-dishes, method of preparation (e.g. purchased or home cooked, fried, steamed) and the ingredients used.

Anthropometric indicators comprising height $(\mathrm{cm})$ and weight $(\mathrm{kg})$ were also measured by trained project staff. Height was measured using a portable stadiometer with a measuring range of $150-2,100 \mathrm{~mm}$ and a graduation of $1 \mathrm{~mm}$. Participants were asked to take off their shoes and stand with their back straight against the stadiometer. Weight was measured with an Omron digital weight scale with a $0 \cdot 1 \mathrm{~kg}$ increment. Participants were asked to remove shoes and jackets for an accurate weight measurement.

A finger-prick test for blood $\mathrm{Hb}$ concentration was performed using Hemocue 201 (Angelholm, Sweden) instruments by trained data collectors. Using a pre-prepared lancet, participants' fingers were pricked, and the first two drops of blood were wiped away. Following this, light pressure to the finger was reapplied to draw blood into a microcuvette. The microcuvette was placed in the Hemocue analyzer and the $\mathrm{Hb}$ measurement was recorded.

\section{Assessment of anaemic status}

Anaemic status was determined using WHO cut-off points based on blood $\mathrm{Hb}$ concentrations ${ }^{(35)}$. Blood $\mathrm{Hb}$ concentrations were converted to $\mathrm{g} / \mathrm{l}$ and placed into categories (Non-Anaemia, Mild, Moderate, Severe) for each participant based on the cut-off values from the appropriate age/sex stratum. Adjustment for elevation was not required and smoking status was not measured. Mild, moderate and severe anaemia were grouped as anaemic to create a binary outcome variable. As a result, anaemic status is considered as $\mathrm{Hb}$ concentration in $\mathrm{g} / \mathrm{l}$ below 120 for non-pregnant women (aged 15+), below 110 for pregnant women and below 130 for men (aged $15+)^{(35)}$.

\section{Measurement of dietary variables}

Soybean was in all but two instances consumed in the form of Tofu or Tempeh. As such, soybean consumption was categorised as 'Neither', 'Tempeh only', 'Tofu only' or 'Tempeh and Tofu'. Tofu and Tempeh had to be a main component of dishes/snacks to be positively classified. Common examples included fried/steamed tofu or tempeh and vegetable dishes made with tempeh and tofu. Diet diversity was measured using the FAO minimum dietary diversity for women guidelines ${ }^{(36)}$. This involves categorising food into ten distinct categories (Grains/white roots and tubers/plantains, Pulses, Nuts and seeds, Milk and milk products, Meat/Poultry/Fish, Eggs, Dark green leafy vegetables, other vitamin A-rich fruits and vegetables, other vegetables and other fruits). High diet diversity was defined as having consumed foods from at least five of these categories, otherwise classified as low diet diversity.

\section{Measurement of BMI}

BMI was calculated by dividing weight in kilograms by height in metres squared. For adults aged 20+ years old, BMI cut-off for Asian populations was employed to categorise individuals as normal (18.5-23), underweight $(<18.5)$ and overweight or obese $(>23)^{(37)}$. For adolescents aged between 15 and 19 years old, BMI for age z-scores was calculated using $\mathrm{WHO}$ AnthroPlus software ${ }^{(38)}$. Overweight or obese was defined as $Z>1$ SD and underweight as $Z<-2 \mathrm{SD}^{(39)}$. Outliers for BMI were considered where BMI for age $z$-scores were $<-5$ or $>5$ for children, and BMI $<14$ for adults.

\section{Soil-transmitted belminth infection status}

Infection with soil-transmitted helminths was determined by analysis of stool samples as part of the overarching sanitation improvement intervention. Participants were approached and asked to provide stool samples that would be collected the next morning. Participants were provided with a sealable plastic container. Parents were instructed on how to obtain stool samples from young children. At the time of collection, stool samples were placed into two centrifuge tubes - a $2 \mathrm{~g}$ sample of faeces was shaken vigorously with $8 \mathrm{ml}$ of $10 \%$ formalin solution, and a $3 \mathrm{~g}$ portion was shaken vigorously with $3 \mathrm{ml} 5 \%$ potassium dichromate. Waste was collected in a clinical waste bag and disposed of appropriately. Centrifuge tubes with stool samples were stored at room temperature away from direct sunlight during storage and transportation to Poltekkes Kemenkes Semarang (Semarang Ministry of Health Polytechnic) for analysis. The identification of STH eggs was performed using the faecal flotation method ${ }^{(40)}$. Species identified were Hookworm, Trichuris trichiura and Ascaris lumbricoides.

\section{Statistical analysis}

Statistical analysis was performed in IBM SPSS version 26. The socio-demographics of the study population was tabulated and the percentage of participants within each sociodemographic category consuming soybean was calculated. Following this, the prevalence of anaemia by socio-demographic and nutritional-related variables was calculated, and crude odds ratios were calculated for anaemic status. Mean $\mathrm{Hb}$ values by age/sex and anaemic status were tabulated. A binary logistic regression was fitted to model the association between soybean consumption and anaemia. Associations between soybean consumption, BMI and diet diversity with anaemia were measured after adjusting for age, sex, education and village in the first model, and then all covariates were mutually adjusted in the second model. 
Table 1 Associations between socio-demographic and nutritional factors with soybean consumption

\begin{tabular}{|c|c|c|c|c|c|c|c|c|c|c|c|}
\hline \multirow[b]{4}{*}{ Study sample } & & \multirow[b]{4}{*}{$n$} & \multirow[b]{4}{*}{$\%$} & \multicolumn{8}{|c|}{ Soybean consumption } \\
\hline & & & & \multirow[b]{3}{*}{ No $n$} & \multirow[b]{3}{*}{$\%^{*}$} & \multicolumn{6}{|c|}{ Yes } \\
\hline & & & & & & \multicolumn{2}{|c|}{ Tofu only } & \multicolumn{2}{|c|}{$\begin{array}{c}\text { Tempeh } \\
\text { only }\end{array}$} & \multicolumn{2}{|c|}{$\begin{array}{l}\text { Tofu and } \\
\text { Tempeh }\end{array}$} \\
\hline & & & & & & $n$ & $\%$ & $n$ & $\%$ & $n$ & $\%$ \\
\hline All & & 763 & 100 & 152 & $19 \cdot 9$ & 100 & $13 \cdot 1$ & 311 & $40 \cdot 7$ & 202 & $26 \cdot 4$ \\
\hline \multirow[t]{2}{*}{ Sex } & Male & 378 & 49.5 & 74 & $19 \cdot 6$ & 45 & 11.7 & 153 & 39.7 & 113 & 29.4 \\
\hline & Female & 385 & $50 \cdot 5$ & 80 & $20 \cdot 8$ & 55 & 14.5 & 158 & $41 \cdot 6$ & 89 & 23.4 \\
\hline \multirow[t]{4}{*}{ Age (years) } & $15-19$ & 121 & $15 \cdot 8$ & 27 & $22 \cdot 3$ & 18 & 14.9 & 45 & $37 \cdot 2$ & 31 & $25 \cdot 6$ \\
\hline & $20-29$ & 199 & $26 \cdot 0$ & 48 & $24 \cdot 1$ & 25 & $12 \cdot 6$ & 77 & 38.7 & 49 & $24 \cdot 6$ \\
\hline & $30-39$ & 215 & $28 \cdot 1$ & 34 & $15 \cdot 8$ & 32 & 14.9 & 89 & $41 \cdot 4$ & 60 & $27 \cdot 9$ \\
\hline & $40-49$ & 230 & $30 \cdot 1$ & 43 & $18 \cdot 7$ & 25 & $10 \cdot 9$ & 100 & 43.5 & 62 & 27 \\
\hline \multirow[t]{4}{*}{ Village } & Topengan & 182 & 23.9 & 36 & $20 \cdot 1$ & 30 & $16 \cdot 8$ & 67 & $37 \cdot 4$ & 46 & $25 \cdot 7$ \\
\hline & Moyosari & 216 & $28 \cdot 3$ & 45 & $20 \cdot 7$ & 27 & $12 \cdot 4$ & 97 & $44 \cdot 7$ & 48 & $22 \cdot 1$ \\
\hline & Rajon & 161 & $21 \cdot 1$ & 37 & $22 \cdot 7$ & 14 & 8.6 & 66 & 40.5 & 46 & $28 \cdot 2$ \\
\hline & Losari & 204 & $26 \cdot 7$ & 34 & $16 \cdot 5$ & 29 & $14 \cdot 1$ & 81 & $39 \cdot 3$ & 62 & $30 \cdot 1$ \\
\hline \multirow[t]{5}{*}{ Education } & No school & 57 & 7.5 & 8 & $14 \cdot 0$ & 9 & $15 \cdot 3$ & 23 & 39 & 20 & 33.9 \\
\hline & Elementary & 327 & $42 \cdot 9$ & 63 & $19 \cdot 3$ & 41 & $12 \cdot 6$ & 141 & 43.4 & 82 & $25 \cdot 2$ \\
\hline & Junior Secondary & 232 & $30 \cdot 4$ & 49 & $21 \cdot 1$ & 34 & $14 \cdot 8$ & 86 & $37 \cdot 6$ & 60 & $26 \cdot 2$ \\
\hline & Senior Secondary & 112 & $14 \cdot 7$ & 26 & $23 \cdot 2$ & 14 & $12 \cdot 1$ & 42 & $36 \cdot 2$ & 33 & 28.4 \\
\hline & College, or higher & 35 & $4 \cdot 6$ & 8 & $22 \cdot 9$ & 2 & $5 \cdot 6$ & 19 & $52 \cdot 8$ & 7 & $19 \cdot 4$ \\
\hline \multirow{3}{*}{ Anthropometry } & Underweight & 35 & 4.6 & 9 & $25 \cdot 7$ & 2 & 8.7 & 10 & 43.5 & 4 & 17.4 \\
\hline & Normal & 544 & $71 \cdot 6$ & 109 & 20 & 56 & 13 & 178 & $41 \cdot 2$ & 117 & $27 \cdot 1$ \\
\hline & Overweight/Obese & 181 & 23.8 & 35 & $19 \cdot 3$ & 42 & 13.5 & 123 & $39 \cdot 7$ & 81 & $26 \cdot 1$ \\
\hline \multirow[t]{2}{*}{ Soil-transmitted helminth infection } & Yes & 75 & $14 \cdot 8$ & 16 & $21 \cdot 3$ & 11 & 14.7 & 28 & $37 \cdot 3$ & 20 & $26 \cdot 7$ \\
\hline & No & 431 & $85 \cdot 2$ & 82 & $19 \cdot 0$ & 54 & $12 \cdot 6$ & 191 & $44 \cdot 4$ & 103 & 24 \\
\hline
\end{tabular}

*Percentages expressed as proportion of participants in soybean consumption categories.

\section{Results}

The demographics of the study population and associations between socio-demographic and nutrition factors with soybean food consumption are presented in Table 1 . The study population was roughly evenly split between males and females as well as across all four villages. Few participants were underweight ( $4.6 \%$ ) and almost a quarter (23.8\%) were overweight or obese combined. Approximately $80 \%$ of the study population consumed soybean products. Little variation in consumption was observed between socio-demographic factors, although there was some indication that tempeh consumption increases with age. Tofu consumption was less common (39.5\%, sum of Tofu only and Tofu and Tempeh) than tempeh consumption $(67 \cdot 1 \%$, sum of Tempeh only and Tofu and Tempeh).

The distribution of mean Hb measurements by age/sex group is presented in Table 2. Mean $\mathrm{Hb}$ concentration was lower among women of all age groups compared with men. There was no trend in $\mathrm{Hb}$ concentration across age groups. Mean $\mathrm{Hb}$ was $4 \mathrm{~g} / \mathrm{dl}$ lower $(10.0 \mathrm{~g} / \mathrm{dl})$ among those with moderate/severe anaemia compared with those who were not anaemic $(14.0 \mathrm{~g} / \mathrm{dl})$.

The prevalence of anaemia by age/sex and crude associations between demographic and nutritional factors with anaemic status are presented in Fig. 1 and Table 3. Almost one-third (30.2\%) of the study population was anaemic. The highest prevalence of anaemia was observed among 20-29-year-old males (38.4\%) and village Rajon (40.5\%).
Moderate anaemia was more common among females in all age groups. The risk factor with strongest positive association with anaemia was underweight status (OR $=2 \cdot 46,95 \%$ $\mathrm{CI}=1.06,5.72, P=0.04)$. Prevalence of anaemia varied between $19.4 \%$ and $40.5 \%$ in villages, and there was a significant negative association between residing in Moyosari compared with Topengan with anaemic status $(\mathrm{OR}=0.49$, $95 \% \mathrm{CI}=0.31,0.78, P<0.05)$. Consuming any category of soybean-based food had a negative association with anaemia, however only the tofu only category had a statistically significant association (OR $=0.54,95 \% \mathrm{CI}=0.31,0.95, P<0.05)$. Diet diversity had a positive association with anaemia ( $\mathrm{OR}=1.23,95 \% \mathrm{CI}=0.90,1 \cdot 69, P=0 \cdot 19)$, although no association between education levels or STH infection was found with anaemia.

Data for STH infection status were incomplete due to loss-to-follow-up in the overarching sanitation improvement intervention and as such was not included in the logistic regression model to retain statistical power.

Results from binary logistic regression analysis for anaemic status are presented in Table 4. Variables in model 1 were adjusted for age, sex and village. After adjusting for these variables, the adjusted OR for anaemia for soybean consumption categories did not change noticeably from crude OR. The significance of the association between high diet diversity and anaemia dropped from $P=0 \cdot 19$ to $P=$ $0 \cdot 08$, and the OR for underweight rose to $2 \cdot 75(95 \% \mathrm{CI}=$ $1.13,6.69, P<0.05)$. After mutually adjusting for all variables in Model 2, the association of tofu only with anaemia 
Table 2 Mean and $95 \% \mathrm{Cl}$ for $\mathrm{Hb}$ measurement by age/sex category

\begin{tabular}{|c|c|c|c|}
\hline & Age (years) & Mean $(\mathrm{g} / \mathrm{dl})$ & $95 \% \mathrm{Cl}$ \\
\hline \multicolumn{2}{|c|}{ Study sample } & $13 \cdot 2$ & $13 \cdot 1,13 \cdot 4$ \\
\hline \multirow{4}{*}{ Males } & $15-19$ & $13 \cdot 5$ & $13 \cdot 1,13 \cdot 9$ \\
\hline & $20-29$ & $13 \cdot 4$ & $13 \cdot 1,13 \cdot 8$ \\
\hline & 30-39 & $14 \cdot 1$ & $13 \cdot 7,14 \cdot 5$ \\
\hline & $40-49$ & $13 \cdot 7$ & $13 \cdot 4,14 \cdot 1$ \\
\hline \multirow[t]{4}{*}{ Females } & $15-19$ & $12 \cdot 8$ & $12 \cdot 2,13 \cdot 4$ \\
\hline & $20-29$ & $12 \cdot 7$ & $12 \cdot 4,13 \cdot 0$ \\
\hline & 30-39 & $12 \cdot 8$ & $12 \cdot 5,13 \cdot 1$ \\
\hline & $40-49$ & $12 \cdot 8$ & $12 \cdot 4,13 \cdot 2$ \\
\hline \multicolumn{2}{|c|}{ Anaemic (moderate/severe) } & $10 \cdot 0$ & $9 \cdot 7,10 \cdot 2$ \\
\hline \multicolumn{2}{|c|}{ Anaemic (mild) } & 11.8 & $11 \cdot 7,11.9$ \\
\hline \multicolumn{2}{|c|}{ Not-anaemic } & $14 \cdot 0$ & $13 \cdot 9,14 \cdot 2$ \\
\hline
\end{tabular}

Values expressed in $\mathrm{g} / \mathrm{dl}$.

only differed slightly $(\mathrm{AOR}=0.53)$ and the association with underweight reduced slightly $(A O R=2 \cdot 59)$. High diet diversity became statistically significant (AOR $=1.40$, $95 \% \mathrm{CI}=1.00,1.97, P<0.05)$. Whilst not statistically significant at $P<0.05$, the associations between tempeh only and tempeh and tofu with anaemia were negative (AOR $=0.71,95 \% \mathrm{CI}=0.46,1 \cdot 09, P=0 \cdot 12$, and $\mathrm{AOR}=$ $0.67,95 \% \mathrm{CI}=0.42,1.06, P=0.09$ respectively).

\section{Discussion}

Results from our study demonstrated that anaemia is prevalent among 15-49-year-old villagers in rural Central Java, and soybean consumption is associated with a reduced risk of anaemia. Our results suggest that routine assessment of anaemia prevalence in Indonesia is critical given the moderate prevalence we observed, and soybean consumption, in particular tofu, could be considered in anaemia-prevention programmes in Indonesia.

The prevalence of anaemia in our study population was $30 \cdot 2 \%$ (Table 3 ), which is categorised as moderate public health significance according to the $\mathrm{WHO}^{(35)}$. Among young males and one particular village anaemia prevalence is almost or at $40 \%$ (Fig. 1(a), Table 3), indicating severe public health significance. Whilst estimates of anaemia prevalence are influenced by the demographics surveyed, our results are similar to the 2008 estimate of $21.1 \%$ among all individuals in the Indonesian Family Life Survey $4^{(6)}$. Among pregnant women in Indonesia, the prevalence of anaemia has actually steadily increased from $40.2 \%$ in 2010 to $44.2 \%$ in $2019^{(5)}$. Thus, strengthened interventions to target anaemia in Indonesia are needed. Updated nation-wide estimates of anaemia prevalence in Indonesia are required for greater understanding of the current situation. Anaemia prevalence was highest among young males whilst we did not quantify smoking status, may be explained by higher rates of smoking in this demographic $^{(41)}$.

We found that soybean consumption is associated with reduced risk of anaemia after adjusting for BMI, diet diversity, STH infection, age, sex and village. Soybean consumption may reduce the risk of anaemia as it is naturally high in $\mathrm{Fe}^{(34)}$. The strongest association was in the 'Tofu only' category $(\mathrm{AOR}=0.53, \quad 95 \% \mathrm{CI}=0.30, \quad 0.95$, $P<0.05$, Table 4). These results are similar to a study among Chinese adults where among women, high consumption of tofu (derived from soybean) compared with low consumption was associated with reduced anaemia risk $(\mathrm{AOR}=0 \cdot 31,95 \% \mathrm{CI}=0 \cdot 20,0 \cdot 47)^{(32)}$. Furthermore, authors of this study found that the odds of anaemia reduced with increasing tofu intake, suggesting a doseresponse relationship. High Fe content of soybean ${ }^{(29)}$ is likely the determining factor in lowering the risk of IDA as it has been demonstrated among American women that $\mathrm{Fe}$ is absorbed from soybean in a clinical study ${ }^{(34)}$. An Indonesian study demonstrating that Fe-fortified tempeh consumption for $10 \mathrm{~d}$ was associated with a significant increase in serum $\mathrm{Hb}$ levels (increase $=0.52 \mathrm{~g} / \mathrm{dl}$, $P<0.05)^{(42)}$ supports our results and the idea that soybean consumption would be protective to IDA by causing an increase in $\mathrm{Hb}$ levels. Interestingly, despite consumption of tofu being greatly lower than tempeh (Table 1), the protective association was stronger for tofu (Table 4). This might be due to the higher Fe content in cooked tofu $(4.87 \mathrm{mg} / 100 \mathrm{~g})$ compared with tempeh $(2.13 \mathrm{mg} / 100$ $g)^{(43)}$. Neither contain the Fe absorption enhancer vitamin $\mathrm{C}$, and so consumption of foods high in vitamin $\mathrm{C}$ in tandem with tofu/tempeh would be expected to have the greatest impact on $\mathrm{Fe}$ and $\mathrm{Hb}$ levels. It might also be possible that by containing more fibre, tempeh (which is made from whole soybeans as opposed to tofu which is a soybean curd) leads to slower Fe absorption and therefore reduced impact on anaemia risk.

The association between underweight and anaemia ( $\mathrm{AOR}=2.59,95 \% \mathrm{CI}=1.05,6.35$, Table 4) is consistent with other studies in south-east Asia where it is thought that underweight women are malnourished and therefore more likely to suffer $\mathrm{IDA}^{(19)}$. We did not observe an association between STH infection and anaemia $($ AOR $=0.97,95 \%$ $\mathrm{CI}=0 \cdot 57,1 \cdot 66$, Table 3 ) despite other studies finding a significant association ${ }^{(24)}$. It is possible that infection intensity and duration were not sufficient to cause anaemia among infected participants, but also due to insufficient statistical power. The notion that there was an association between high diet diversity and anaemia is counterintuitive. There may be other confounding variables not adjusted for in this study, and this relationship requires further investigation.

Encouraging soybean consumption as part of a staple diet could be effective in preventing anaemia when coupled with Fe supplementation. This is because whilst issues of non-compliance and inconsistent use of Fe supplementation in Indonesia have been reported ${ }^{(11)}$, the consumption of soybean in our study was almost $80 \%$, which was expected given it is a local staple (Table 1). Whilst Fe fortification of wheat flour has been mandatory in Indonesia since $2001^{(44)}$, consumption of wheat flour 

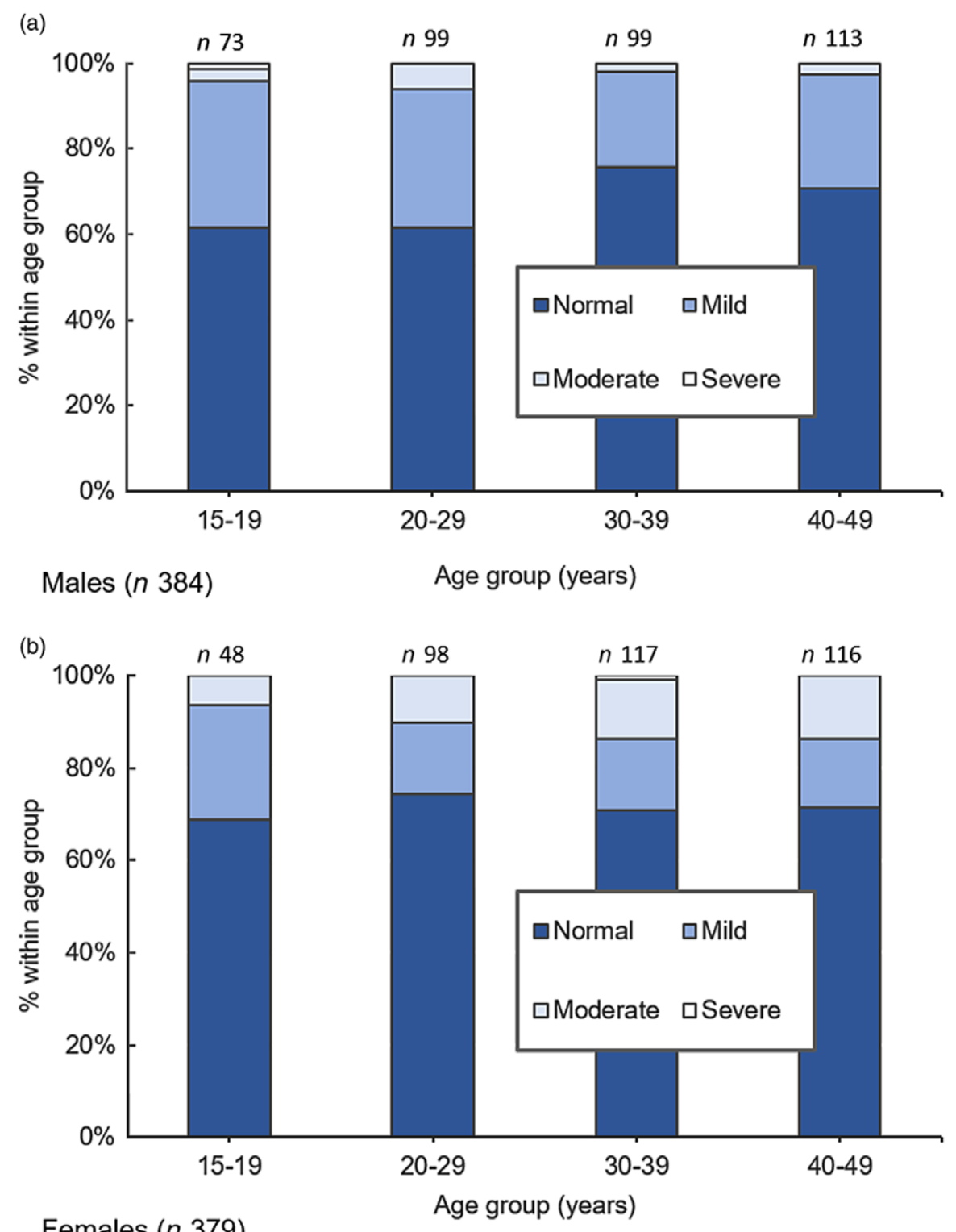

Fig. 1 Prevalence (\%) of anaemia by age and sex group

products among adults in our study was very low; the dominant carbohydrate source was white rice ${ }^{(45)}$. Only recently has Fe fortification of rice programmes began in Indonesia, but with limited success in increasing serum $\mathrm{Hb}$ and ferritin levels ${ }^{(44)}$. The added health benefits of soybean should also be mentioned, including a recent study that found that a drink made from soybean protein had anti-inflammatory properties among pregnant women in Malaysia ${ }^{(46)}$.

Our study has several limitations. We did not report the consumption of soybean as a continuous numeric variable due to uncertainty in estimating the amounts of soybean products present in composite dishes. This could cause our association between soybean and anaemia to be underestimated as greater consumption of soybean which would provide greater Fe intake would be assumed to provide an even greater protective association with anaemia.
Because the food recall was only relevant to a single day, due to chance there may be individuals who regularly consume soybean but not in the $24 \mathrm{~h}$ prior to the data collection. This would bias the association towards the null. However, post hoc analysis of a FFQ that reports historical consumption among the same study population as part of the overarching study revealed a negative association between soybean and anaemia. This indicated that the association reported from the 24-h food recall is reliable. Furthermore, some socio-economic and other health conditions that may associate with anaemia (e.g. HIV, inflammation) were not included in the model and we did not measure smoking behaviour which could affect the associations observed. The high prevalence of anaemia among young males may be driven by smoking. However, whilst these variables may correlate with anaemia, they most 
Table 3 Bivariate analysis of the associations between socio-demographic and nutrition factors with anaemia

\begin{tabular}{|c|c|c|c|c|c|c|}
\hline & & Anaemic $n$ & $\%$ & OR & $95 \% \mathrm{Cl}$ & $P$-value \\
\hline Study sample & & 231 & $30 \cdot 4$ & $\mathrm{~N} / \mathrm{A}$ & & $\mathrm{N} / \mathrm{A}$ \\
\hline \multirow[t]{4}{*}{ Village } & Topengan & 59 & $32 \cdot 8$ & - & & - \\
\hline & Moyosari & 42 & $19 \cdot 4$ & 0.49 & $0.31,0.78$ & 0.002 \\
\hline & Rajon & 66 & 40.5 & 1.40 & $0.90,2.17$ & 0.14 \\
\hline & Losari & 64 & $31 \cdot 1$ & 0.92 & $0.60,1.42$ & 0.72 \\
\hline \multirow[t]{5}{*}{ Education } & No school & 16 & $27 \cdot 1$ & - & & - \\
\hline & Elementary & 97 & 29.8 & $1 \cdot 14$ & $0.61,2.13$ & 0.67 \\
\hline & Junior secondary & 71 & 30.9 & $1 \cdot 20$ & $0.63,2.27$ & 0.58 \\
\hline & Senior secondary & 39 & 33.6 & 1.36 & $0.68,2.72$ & 0.38 \\
\hline & College or higher & 8 & $22 \cdot 2$ & 0.77 & $0.29,2.03$ & 0.60 \\
\hline \multirow[t]{3}{*}{ Anthropometry } & Normal & 133 & 30.7 & - & & - \\
\hline & Underweight & 12 & $52 \cdot 2$ & 2.46 & $1.06,5.72$ & 0.04 \\
\hline & Overweight/obese & 86 & $27 \cdot 7$ & 0.87 & $0.63,1.20$ & 0.38 \\
\hline \multirow[t]{2}{*}{ Soil-transmitted helminth infection } & Yes & 22 & $29 \cdot 3$ & 0.97 & $0.57,1.66$ & 0.92 \\
\hline & No & 129 & 29.9 & - & & - \\
\hline \multirow[t]{2}{*}{ Dietary diversity } & Low & 138 & 28.5 & - & & \\
\hline & High & 93 & 33.0 & 1.23 & $0.90,1.69$ & 0.19 \\
\hline \multirow[t]{4}{*}{ High Fe food consumption } & No soybean & 56 & $36 \cdot 8$ & - & & - \\
\hline & Tempeh only & 92 & 29.5 & 0.72 & $0.48,1.08$ & 0.11 \\
\hline & Tofu only & 24 & 24.0 & 0.54 & $0.31,0.95$ & 0.03 \\
\hline & Tempeh and Tofu & 59 & $29 \cdot 2$ & 0.71 & $0.45,1.11$ & 0.13 \\
\hline
\end{tabular}

Odds ratios in bold typeface are statistically significant at $P<0.05$.

Three participants excluded due to missing data on at least one covariate.

Table 4 Binary logistic regression for anaemic status

\begin{tabular}{|c|c|c|c|c|c|c|c|}
\hline & & \multicolumn{3}{|c|}{ Model $1^{*}$} & \multicolumn{3}{|c|}{ Model 2† } \\
\hline & & AOR & $95 \% \mathrm{Cl}$ & $P$ & AOR & $95 \% \mathrm{Cl}$ & $P$ \\
\hline \multirow{4}{*}{ Soybean consumption } & No soybean $(n 150)$ & & & & & & \\
\hline & Tempeh only ( $n$ 310) & 0.74 & $0.49,1 \cdot 12$ & $0 \cdot 16$ & 0.71 & $0.46,1.09$ & 0.12 \\
\hline & Tofu only ( $n$ 99) & 0.55 & $0.31,0.98$ & 0.04 & 0.53 & $0.30,0.95$ & 0.03 \\
\hline & Tempeh and Tofu $(n$ 201) & 0.68 & $0.43,1.08$ & $0 \cdot 10$ & 0.67 & $0.42,1.06$ & 0.09 \\
\hline \multirow[t]{3}{*}{ Anthropometry } & Normal $(n 544)$ & & & & & & \\
\hline & Underweight (n 35) & 2.75 & $1.13,6.69$ & 0.03 & 2.59 & $1.05,6.35$ & 0.04 \\
\hline & Overweight/obese ( $n$ 181) & 1.07 & $0.75,1.52$ & 0.73 & 1.03 & $0.72,1.48$ & 0.87 \\
\hline \multirow[t]{2}{*}{ Diet diversity } & Low $(n$ 477) & & & & & & \\
\hline & High (n 283) & 1.34 & $0.96,1.86$ & 0.08 & 1.40 & $1.00,1.97$ & 0.05 \\
\hline
\end{tabular}

Total $n 760$.

Odds ratios in bold typeface are statistically significant at $P<0.05$.

${ }^{*}$ Adjusted for age, sex and village.

†Adjusted for age, sex, village, soybean consumption, anthropometry and diet diversity.

likely do not correlate with soybean consumption in this study context, therefore we do not expect that adjusting for these variables would have great effect on the association between soybean consumption and anaemia. We did not record pregnancy status among women and as such we cannot report our association directly among pregnant women. Measuring blood $\mathrm{Hb}$ concentration is not as accurate as recording blood ferritin levels from a serum blood sample to assess for Fe-deficient anaemia, nor does it permit the possibility to assess non-Fe deficient anaemia.

\section{Conclusion}

Results from our study indicate that anaemia prevalence is relatively consistent with reported nation-wide data. Soybean consumption, in particular tofu, was associated with a lower risk of anaemia. Soybean, unlike other meat or animal products that might be encouraged to prevent anaemia, is considerably affordable in Indonesia. Furthermore, it is a culturally acceptable food with other added health and dietary benefits. Consumption of soybean was high, and future research should evaluate the quantity of soybean consumed and its association with anaemia. Encouraging the consumption of soybean products among demographics at high risk of anaemia may work in tandem with existing interventions to prevent anaemia in Indonesia.

\section{Acknowledgements}

Acknowledgements: The authors would like to thank all the Wonosobo residents who assisted us with this research, 
and particularly the village heads who dedicated their time and attention to this project amongst all their other responsibilities. We also thank the dedicated team of data collectors in Wonosobo. Financial support: We acknowledge funding from the UBS-Optimus Foundation and the National Health and Medical Research Council. Authorship: MK, DS and DG conceptualised the study. JK developed and managed the database. JK, BL and SA provided support for data collection tool development and activities. CL and HS conceptualised the paper. CL and HS analysed the data and CL wrote the manuscript draft. MK, HS, DG and CL edited the manuscript to produce the final copy. BL and SA provided administrative support in data collection. All authors contributed to the final manuscript editing. Conflict of interest: The authors have no conflicts of interest to declare. Ethics of buman subject participation: This study was conducted according to the guidelines laid down in the Declaration of Helsinki and all procedures involving research study participants were approved by the Griffith University Human Research Ethics Committee (Protocol number 2014/541) and the Australian National University Human Research Ethics Committee (Protocol number 2017/038). Written informed consent was obtained from all subjects.

\section{References}

1. Chaparro CM \& Suchdev PS (2019) Anemia epidemiology, pathophysiology, and etiology in low- and middle-income countries. Ann NY Acad Sci 1450, 15-31.

2. Miller JL (2013) Iron deficiency anemia: a common and curable disease. Cold Spring Harb Perspect Med 3, a011866.

3. Lipoeto NI \& Nindrea RD (2020) Nutritional contributors to maternal anemia in Indonesia: chronic energy deficiency and micronutrients. Asia Pac J Clin Nutr 29, S9-S17.

4. Mansyur M, Khoe LC, Karman MM et al. (2019) Improving workplace-based intervention in Indonesia to prevent and control anemia. I Prim Care Community Health 10 , 2150132719854917.

5. World Bank \& World Development Indicators (2021) Prevalence of Anemia among Pregnant Women (\%) Indonesia. https://data.worldbank.org/indicator/SH.PRG. ANEM?locations=ID (accessed July 2021).

6. Barkley JS, Kendrick KL, Codling K et al. (2015) Anaemia prevalence over time in Indonesia: estimates from the 1997, 2000, and 2008 Indonesia Family Life Surveys. Asia Pac J Clin Nutr 24, 452-455.

7. World Bank (2013) The Double Burden of Malnutrition in Indonesia. Jakarta. (C) World Bank. License: CC BY 3.0 IGO. https://openknowledge.worldbank.org/handle/10986/17007 (accessed August 2021)

8. Kementerian Kesehatan (2019) Laporan Riset Kesehatan Dasar (Basic Health Research Report) (Riskesdas) 2018. Jakarta: Badan Litbangkes, Kemenkes RI.

9. Lestari S, Fujiati I, Keumalasari D et al. (2018) The Prevalence of Anemia in Pregnant Women and Its Associated Risk Factors in North Sumatera, Indonesia. IOP Conference Series: Earth and Environmental Science. https:// iopscience.iop.org/article/10.1088/1755-1315/125/1/012195 (accessed April 2021).

10. Scholl TO (2005) Iron status during pregnancy: setting the stage for mother and infant. Am J Clin Nutr 81, 1218S-1222S.
11. Seu MMV, Mose JC, Panigoro R et al. (2019) Anemia prevalence after iron supplementation among pregnant women in midwifes practice of primary health care facilities in Eastern Indonesia. Anemia 2019, 1413906.

12. Juffrie M, Helmyati S \& Hakimi M (2020) Nutritional anemia in Indonesia children and adolescents: diagnostic reliability for appropriate management. Asia Pac J Clin Nutr 29, S18-S31.

13. Schultink W, van der Ree M, Matulessi P et al. (1993) Low compliance with an iron-supplementation program: a study among pregnant women in Jakarta, Indonesia. Am J Clin Nutr 57, 135-139.

14. Roche ML, Bury L, Yusadiredja IN et al. (2018) Adolescent girls' nutrition and prevention of anaemia: a school based multisectoral collaboration in Indonesia. BMJ 363, k4541.

15. Intiful FD, Wiredu EK, Asare GA et al. (2016) Anaemia in pregnant adolescent girls with malaria and practicing pica. Pan Afr Med J 24, 96.

16. Nelson M (1996) Anaemia in adolescent girls: effects on cognitive function and activity. Proc Nutr Soc 55, 359-367.

17. Seminar AU, Briawan D, Khomsan A et al. (2020) Awareness about anaemia and Weekly Iron-Folic Acid Supplementation (WIFAS) among school-going adolescent girls and parents in East Java and East Nusa Tenggara, Indonesia. J Nutr Sci Vitaminol 66, S111-S117.

18. Didzun O, De Neve JW, Awasthi A et al. (2019) Anaemia among men in India: a nationally representative crosssectional study. Lancet Glob Health 7, e1685-e1694.

19. Sunuwar DR, Singh DR, Chaudhary NK et al. (2020) Prevalence and factors associated with anemia among women of reproductive age in seven South and Southeast Asian countries: evidence from nationally representative surveys. PLOS ONE 15, e0236449.

20. Mohammed SH, Habtewold TD, Muhammad F et al. (2019) The contribution of dietary and non-dietary factors to socioeconomic inequality in childhood anemia in Ethiopia: a regression-based decomposition analysis. BMC Res Notes 12, 646.

21. Ahmed F \& Al-Sumaie MA (2011) Risk factors associated with anemia and iron deficiency among Kuwaiti pregnant women. Int J Food Sci Nutr 62, 585-592.

22. Suega K, Dharmayuda TG, Sutarga IM et al. (2002) Iron-deficiency anemia in pregnant women in Bali, Indonesia: a profile of risk factors and epidemiology. Southeast Asian J Trop Med Public Health 33, 604-607.

23. Abriha A, Yesuf ME \& Wassie MM (2014) Prevalence and associated factors of anemia among pregnant women of Mekelle town: a cross sectional study. BMC Res Notes 7, 888.

24. Burdam FH, Hakimi M, Thio F et al. (2016) Asymptomatic vivax and falciparum parasitaemia with helminth co-infection: major risk factors for anaemia in early life. PLOS ONE 11, e0160917.

25. Gilles HM, Williams EJ \& Ball PA (1964) Hookworm infection and anaemia. An epidemiological, clinical, and laboratory study. QJ Med 33, 1-24.

26. Agustina R, Nadiya K, Andini EA et al. (2020) Associations of meal patterning, dietary quality and diversity with anemia and overweight-obesity among Indonesian school-going adolescent girls in West Java. PLOS ONE 15, e0231519.

27. Jackson J, Williams R, McEvoy M et al. (2016) Is higher consumption of animal flesh foods associated with better iron status among adults in developed countries? A systematic review. Nutrients $\mathbf{8}, 89$.

28. FAO (2013) Current Worldwide Annual Meat Consumption per Capita: Food and Agriculture Organization of the United Nations. http://faostat.fao.org/site/610/DesktopDefault.aspx? PageID $=610 \#$ ancor) (accessed August 2021).

29. Wijaya-Erhardt M, Muslimatun S \& Erhardt JG (2011) Fermented soyabean and vitamin C-rich fruit: a possibility to circumvent the further decrease of iron status among 
iron-deficient pregnant women in Indonesia. Public Health Nutr 14, 2185-2196.

30. Ningrum IH \& Riptanti E (2018) Analysis of soybean production and import trends and its import factors in Indonesia. IOP Conf Ser Earth Environ Sci 142, 012059.

31. Shiga K, Hara H, Okano G et al. (2003) Ingestion of watersoluble soybean fiber prevents gastrectomy-induced iron malabsorption, anemia and impairment of voluntary running exercise performance in rats. J Nutr 133, 1120-1126.

32. Shi Z, Hu X, Yuan B et al. (2008) Strong negative association between intake of tofu and anemia among Chinese adults in Jiangsu, China. J Am Diet Assoc 108, 1146-1153.

33. Xu J, Li Y, Huo J et al. (2019) Supplementing fortified soybean powder reduced anemia in infants and young children aged 6-24 months. Nutr Res 63, 21-33.

34. Murray-Kolb LE, Welch R, Theil EC et al. (2003) Women with low iron stores absorb iron from soybeans. Am J Clin Nutr 77, 180-184.

35. WHO (2011) Haemoglobin Concentrations for the Diagnosis of Anaemia and Assessment of Severity. Geneva: World Health Organization.

36. FAO (2021) Minimum Dietary Diversity for Women. Rome: FAO.

37. Consultation WHO (2004) Appropriate body-mass index for Asian populations and its implications for policy and intervention strategies. Lancet 363, 157-163.

38. World Health Organization (2007) WHO AnthroPlus Software: Software for Assessing Growth and Development of the World's Children. Geneva: WHO.
39. de Onis M, Onyango AW, Borghi E et al. (2007) Development of a WHO growth reference for school-aged children and adolescents. Bull World Health Organ 85, 660-667.

40. Inpankaew T, Schar F, Khieu V et al. (2014) Simple fecal flotation is a superior alternative to guadruple Kato Katz smear examination for the detection of hookworm eggs in human stool. PLoS Negl Trop Dis $\mathbf{8}$, e3313.

41. Amalia B, Cadogan SL, Prabandari YS et al. (2019) Sociodemographic inequalities in cigarette smoking in Indonesia, 2007-2014. Prev Med 123, 27-33.

42. Wulandhari A, Supriyana S, Bahiyatun B et al. (2017) Effect of fe-fortified tempe on hematologic status in pregnant mothers with anemia. Belitung Nurs J 3, 370-375.

43. United States Department of Agriculture (2021) USDA Food Data Central. https://fdc.nal.usda.gov (accessed August 2021).

44. Dewi NU \& Mahmudiono T (2021) Effectiveness of food fortification in improving nutritional status of mothers and children in Indonesia. Int $J$ Environ Res Public Health 18, 2133.

45. Lowe C, Kelly M, Sarma H et al. (2021) The double burden of malnutrition and dietary patterns in rural Central Java, Indonesia. Lancet Reg Health West Pac 14, 100205.

46. Winarsi H, Yuniaty A \& Ramadhan GR (2020) Anti-inflammatory effects of functional milk drink enriched with soya bean sprout protein in breastfeeding mothers. Malays J Nutr 26, 289-302. 